\begin{abstract}
Iranica
Abstracta Iranica Revue bibliographique pour le domaine irano-aryen

Volume 34-35-36 | 2017

Comptes rendus des publications de 2011-2013
\end{abstract}

\title{
Timothy May. The Mongol Conquests in World History
}

\section{Denise Aigle}

\section{(2) OpenEdition}

\section{Journals}

\section{Édition électronique}

URL : http://journals.openedition.org/abstractairanica/41830

DOI : 10.4000/abstractairanica.41830

ISSN : 1961-960X

Éditeur :

CNRS (UMR 7528 Mondes iraniens et indiens), Éditions de l'IFRI

\section{Référence électronique}

Denise Aigle, "Timothy May. The Mongol Conquests in World History », Abstracta Iranica [En ligne], Volume 34-35-36 | 2017, document 12, mis en ligne le 30 décembre 2016, consulté le 29 septembre 2020. URL : http://journals.openedition.org/abstractairanica/41830 ; DOI : https://doi.org/10.4000/ abstractairanica. 41830

Ce document a été généré automatiquement le 29 septembre 2020.

Tous droits réservés 


\title{
Timothy May. The Mongol Conquests in World History
}

\author{
Denise Aigle
}

\section{RÉFÉRENCE}

Timothy May. The Mongol Conquests in World History. London, Reaktion Books Ltd, 2012, 320 p. ISBN : 978-1861898078

1 On peut considérer que l'Empire mongol a ouvert la voie à l'ère moderne. Dans sa plus grande extension, il s'étendait de la mer de Chine à l'Anatolie, des Carpates et de la Sibérie à l'Hindou Kush et au golfe Persique. L'Empire mongol a changé la carte politique de l'Eurasie en l'ouvrant aux échanges économiques et culturels sur une vaste échelle allant de l'Europe à l'Extrême-Orient et au monde musulman. L'ouvrage de T. May comporte deux parties : "The Mongol Conquests as Catalyst » et « The Chinggis Exchange ", précédées d'une introduction concise sur l'historiographie du sujet et la notion de « World History » (p. 7-23).

2 Dans le premier chapitre (" The Formation of the Mongol Empire », p. 27-57), T. May donne un récit très clair des conquêtes mongoles. Il mentionne qu'un ulus mongol de Khamag fut créé par Gengis Khan pour remplacer les vieilles identités ethniques comme les Kereit et les Naiman (p. 36-37). May utilise ce terme comme un nom propre et suggère qu'il existait un ulus mongol de Khamag à l'époque pré-gengiskhanide et que ce dernier servit de prototype au " grand État mongol (yeke monggol ulus)» (p. 213). Cependant, selon Igor de Rachewiltz, le khamag ulus désignait simplement l'ensemble des Mongols (voir The Secret History of the Mongols, Leyde, 2004, vol. 1, p. 296). Le chapitre suivant ("The Dissolution of the Empire ", p. 59-80) décrit brièvement comment se sont établis les différents khanats (Ilkhanat, Chaghatai et Horde d'Or) et comment ils ont disparu avec les conquêtes timourides. Enfin, dans le troisième chapitre (« The World of 1350: A Global World », p. 81-106), l’A. présente de manière 
rapide les différents pouvoirs que ont vu le jour en Eurasie après la dissolution de l'Empire mongol.

3 La seconde partie concerne l'impact mongol sur la diffusion des idées, les technologies, les matières premières et les produits finis. Il désigne cet impact sous les termes « The Chinggis Exchange ", chacun centré sur une dimension spécifique des échanges auxquels l'Empire mongol a donné lieu en Eurasie : commerce (p. 109-129), art militaire et technologie (p. 130-157), administration (p. 158-171), religion (p. 172-198), peste (p. 199-210), migrations, tendances démographiques (p. 211-231) et échanges culturels ( $\mathrm{p}$. 232-256). L'unification d'une grande partie de l'Eurasie sous un seul régime impérial a considérablement réduit les coûts et les dangers du commerce et des voyages. Pendant toute cette période, marchands, aventuriers européens et missionnaires ont pu atteindre, pour la première fois, l'Extrême-Orient. À leur retour, ils ont rapporté des techniques, des connaissances et des savoirs nouveaux. L'apprentissage des langues orientales s'est développé et des dictionnaires et glossaires multilingues ont vu le jour à des fins commerciales ou missionnaires. On peut d'ailleurs considérer que cette période marque les débuts de l'orientalisme (voir l'ouvrage récent de Kim M. Philips, Before Orientalism: Asian Peoples and Cultures in European Travel Writing, 1245-1510, Philadelphie, 2013). L'Empire mongol a également favorisé la progression du christianisme latin en Extrême-Orient avec l'installation de missions (voir Thomas Tanase, "Jusqu'aux limites du monde " : la papauté et la mission franciscaine, de l'Asie de Marco Polo à l'Amérique de Christophe Colomb, Rome, 2013). Le chapitre sur l'art militaire est basé sur le livre de T. May (The Mongol Art of War: Chinggis Khan and the Mongol Military System, Yardley, Westholme Publishing, 2007). Il constitue un bon résumé des techniques militaires utilisées par les Mongols et témoigne de leur influence à l'époque moderne.

Il est bien connu, notamment grâce aux travaux de Thomas Allsen, que les Mongols ont instauré un système cohérent et efficace de taxation et de recensement des populations dans l'empire. La période mongole est caractérisée par des échanges culturels sans précédent entre l'Extrême-Orient, le monde musulman et l'Occident. Ils furent la conséquence des liens politiques entre les grands khans mongols de Chine, les Yüan et la dynastie mongole d'Iran, les Ilkhans. Les territoires qu'ils dominaient ont constitué les domaines les plus avancés culturellement à cette époque en matière d'échanges entre la Chine et l'Islam (médecine, art, techniques, etc.). L'un des acteurs majeurs de ces transferts culturels fut le ministre ilkhanide, Rašīd al-Dīn. Il est l'auteur de traités sur la médecine, l'agronomie, et il a rédigé une « Histoire universelle » au sens propre du terme, le Jāmi al-tawārīH, qui comporte l'histoire des Mongols, mais aussi de la Chine, de l'Inde, des Arméniens, des Francs et des juifs. Sans les conquêtes mongoles, un tel projet n'aurait pu se réaliser. Ce livre sera utile aux étudiants et à tout lecteur qui souhaite s'informer sur une période charnière de l'histoire mondiale. 


\section{AUTEURS}

DENISE AIGLE

CNRS-UMR 8167 « Orient et Méditerranée » 